\title{
PENGAYAAN MATERI PRAKTIK OPERASIONAL RESTORAN HOTEL BAGI SISWA SMKN DKI JAKARTA
}

\author{
Lyly Soemarni ${ }^{1}$, Rahmat Kusnedi ${ }^{2}$, Andi Guna ${ }^{3}$, \\ Said Gibran Galeb ${ }^{4}$, Valerie Nathania ${ }^{5}$ \\ Program Studi Pariwisata Institut Sains dan Teknologi Pradita \\ lyly.soemarni@pradita.ac.id, rahmat.kusnedi@pradita.ac.id, andi.guna@pradita.ac.id
}

\begin{abstract}
Abstrak
Bentuk pembelajaran dengan metode praktikum merupakan salah satu cara untuk menyampaikan materi pelajaran kepada siswa. Manfaat dari praktikum adalah melatih keterampilannya siswa secara aktif dan memberikan kesempatan bagi siswa menerapkan pengetahuan dan keterampilan teknis pada saat yang bersamaan sehingga memberikan pemahaman secara utuh atas materi pelajaran. SMKN Pariwisata memiliki jurusan Tata Boga dan Tata Hidang yang menerapkan metode pembelajaran praktikum dan kegiatan praktikum jurusan tata boga dan tata hidang dilakukan di dalam laboratorium yang terpisah. SMKN melihat adanya kebutuhan melakukan praktikum bersama antar siswa jurusan Tata Boga dan Tata Hidang sehingga keterampilan teknis siswa dapat diterapkan dalam lingkungan yang mendekati kondisi di industri.

Kegiatan pengabdian ini merupakan bagian dari program pengayaan materi praktikum bagi siswa SMKN dan pelaksanannya mengambil tempat di laboratorium restoran, laboratorium Kitchen dan Bakery \& Pastry serta melibatkan dosen pengajar serta mahasiswa program studi Pariwisata. Tujuan kegiatan ini untuk memberikan pengalaman praktis bagi siswa dalam melakukan kegiatan praktikum bersama dan bersinerji antar siswa Tata Boga dan Tata Hidang.

Metode kegiatan adalah siswa Tata Boga membuat menu Balinese dari makanan pembuka, sup, utama sampai penutup dengan dipandu oleh seorang Chef instruktur dan dibantu mahasiswa dalam menyiapkan peralatan. Pada waktu yang bersamaan siswa Tata Hidang akan menyusun meja kursi serta menyiapkan peralatan yang dibutuhkan untuk layanan prasmanan (buffet) dan pemberian materi tentang layanan prasmanan dan praktik pembuatan minuman. Serta demonstrasi fruit carving dan ice carving serta mencoba teknik carving sederhana. Kemudian siswa Tata Hidang menjalankan perannya sebagai greeter pembuat minuman dan waiter saat tamu datang ke restoran.

Manfaat program ini adalah memberikan pengalaman atas kegiatan operasional sebuah restoran hotel dan membangun bentuk kerjasama antar siswa serta memberikan pengalaman dalam mengolah makanan dalam jumlah banyak dengan waktu terbatas serta pengalaman memberikan layanan kepada tamu undangan.
\end{abstract}

Kata Kunci: Metode praktikum, SMKN, restoran, praktik bersama

\section{PENDAHULUAN}

Praktik Bersama atau Joint-Practicum di institusi pendidikan adalah jenis kegiatan praktik yang mengkolaborasikan antara satu kelompok institusi dengan kelompok institusi lainnya.

Praktikum ini memiliki manfaat dapat melatih keterampilan siswa secara aktif dan memberikan kesempatan bagi siswa dalam menerapkan 
pengetahuan, keterampilan teknis, dan kolaborasi antar anggota tim pada saat yang bersamaan (Hardina, Middleton, Montana, \& Simpson, 2007). Sebagaimana diungkapkan oleh Lall \& Sharma (2009) tentang pembentukan pengetahuan dan keterampilan professional melalui program pelatihan dan pengembangan. Selanjutnya, praktik ini diimplementasikan kedalam operasional restoran yang terbagi menjadi 2 (dua) divisi, tata hidang dan tata boga.

Tata Hidang secara umum adalah aktivitas dan cara menyusun, mempersiapkan, memperindah, dan menghidangkan makanan dan minuman kepada tamu dengan memperhatikan multi pelayananpelayanan yang diberikan (Mertayasa, 2012). Multi pelayanan yang dimaksud seperti keramah-tamahan, kecepatan, dan ketelitian. Kompetensi tersebut menjadi dasar yang dimiliki oleh setiap pekerja dalam menjalankan operasional tata hidang. Selain itu, kefokusan pada saat menghidangkan juga perlu diperhatikan karena secara langsung berhadapan berhadapan dengan tamu dan akan sangat terlihat pada baik atau buruknya kinerja suatu restoran.

Tata Boga dapat diartikan sebagai suatu seni dalam mengolah masakan yang mencakup keseluruhan ruang lingkup makanan, mulai dari tahap persiapan, pengolahan, hingga menghidangkan makanan (Bartono, 2010). Di dunia tata boga, selain mempelajari masakan tradisional, juga mempelajari masakan internasional dari berbagai penjuru dunia, Selain itu, tata boga memperhatikan pemahaman yang komprehensif seperti kualitas, rasa, estetika, dan kandungan gizi/nutrisi yang terdapat pada suatu sajian makanan (Setiawan, 2008). Walaupun demikian, mengolah suatu masakan membutuhkan keahlian dasar yang harus dimiliki setiap orang. Keahlian dasar dapat ditemukan secara otodidak melalui bakat dan turuntemurun dari orangtua ataupun mempelajarinya saat berada di Sekolah Menengah ataupun Sekolah Tinggi yang memiliki jurusan tata boga.

\section{Seni Mengukir (Art Carving) di hospitality} dapat ditemui pada acara-acara spesial seperti event pernihakan, event peluncuran produk perusahaan, dan lainnya. Seni mengukir menggunakan alat untuk membentuk suatu objek dengan menghilangkan beberapa bagian-bagian material tententu. Objek yang sering digunakan di restoran dan diterapkan pada benda padat, seperti adalah es, buah, dan sayuran. Menurut Idayati \& Pratiwi (2008), sebuah dekorasi memiliki fungsi untuk membuat suatu makanan dapat menjadi menarik dan menggugah selera makan, seni mengukir adalah kebiasaan Timur yang mana pada saat itu banyak diadopsi oleh koki kreatif dan seniman. Sebagai contoh, Jepang dan Thailand menganggap presentasi makanan hasil dari seni ukir melebihi kecantikan aksesoris/perhiasan.

Tujuan kegiatan ini adalah memberikan pengalaman atas kegiatan operasional sebuah restoran hotel dan membangun bentuk kerjasama antar siswa serta memberikan pengalaman dalam mengolah makanan dalam jumlah banyak dengan waktu terbatas. Selain itu, peserta juga mempelajari bagaimana langkah-langkah persiapan pada saat/sebelum restoran dibuka. Praktik bersama 
(Joint-Practicum) dilakukan dengan seksama dan penuh dengan persiapan yang matang agar pelaksanaan operasional restoran menjadi lancar. Juga, memperoleh pengalaman melayani tamu undangan nyata seperti di restoran hotel komersil.

\section{METODE}

Metode praktik bersama (Joint-Practicum) dipilih sebagai metode inovatif untuk kegiatan pengabdian masyarakat dengan mengkolaborasikan 2 (dua) Sekolah Menengah Kejuruan (SMKN) dengan mahasiswa Program Studi Pariwisata. Metode ini digunakan bertujuan untuk membantu individu atau kelompok dalam meningkatkan fungsi dan keberdayaannya (Poulin, 2005). Kegiatan ini dilaksanakan 2 (dua) hari; Selasa, 09 April dan Kamis, 11 April 2019, dengan judul "Pengayaan Materi Praktik Operasional Restoran Hotel bagi Siswa SMKN Jakarta”. Peserta yang terlibat pada kegiatan ini berjumlah 30 siswa/i dengan 3 guru pendamping dari SMKN 57 sementara SMKN 27 berjumlah 40 siswa/siswi dengan 6 guru pendamping. Untuk pelaksanaan kegiatan PKM dikaitkan dengan materi pembelajaran mata kuliah Operasional Perhelatan Bisnis sub tema penyelenggaraan Workshop yang melibatkan mahasiswa Program studi Pariwisata semester 2 sebanyak 52 mahasiswa. Keterlibatan mahasiswa ada dalam beberapa divisi yaitu Sekretariat/ registrasi, dokumentasi, mentor kitchen/pastry/tata hidang, Liaison Officer pendamping guru, tim preparation Lab (kitchen, pastry, restoran), Tim Ice/ Fruit Carving dan logistik mahasiswa dan siswa.
Lokasi PkM diselenggarakan di Pradita Institute, Tangerang dengan menggunakan fasilitas laboratorium restaurant \& kitchen. Kampus tersebut dipilih karena memiliki laboratorium praktik yang terintegrasi antara ruang restaurant \& kitchen yang didesain khusus layaknya berada di industri nyata. Hal ini bertujuan agar siswa/siswi dapat terbiasa dengan suasana industri saat ini. Selain itu, kelengkapan peralatan yang dimiliki kampus tersebut juga menjadi pertimbangan untuk menunjang kelancaran proses praktik. Selama praktik, siswa/siswi dibimbing oleh 3 (tiga) tim dosen, diantaranya adalah Chef Tata Boga, Chef Pastry, dosen pengajar Tata Hidang dan dibantu oleh mahasiswa sebagai mentor di masing-masing bagian.

Secara teknis, kegiatan PkM dibagi menjadi 2 (dua) tahapan proses operasional restoran; proses persiapan, dan proses pelaksanaan. Kegiatan dilaksanakan dengan pembagian kelompok siswa menjadi 3 kelompokbesar yaitu divisi tata hidang, food production, dan bakery. Metode praktik tata hidang yang digunakan mengacu pada konsep 7 (tujuh) langkah dasar operasional tata hidang dari Wiwoho (2008).

\section{HASIL DAN PEMBAHASAN}

Secara keseluruhan, siswa-siswi SMKN mempraktikan teori-teori dan standard operational procedure (SOP) yang sudah mereka pelajari atau mungkin belum pernah ditemuinya pada saat di sekolah. Berikut adalah hasil dan pembahasan dari proses pengayaan praktik operasional restoran hotel, Pendidikan 976 
yang terbagi menjadi 2 (dua) tahapan proses operasional; persiapan dan pelaksanaan.

\section{Proses Persiapan}

\section{a. Divisi Tata Hidang}

Siswa/siswi diajarkan tentang cara menata meja makan (table setup), seperti mengatur dan melengkapi meja dengan peralatan yang sesuai dengan jenis hidangan yang akan disajikan. Di sesi persiapan awal, peserta diperkenalkan dengan pengetahuan dasar seperti nama-nama peralatan yang dipergunakan. Peralatan yang didemonstrasikan oleh pengajar antara lain; chinaware $(B \& B$ plate dan tea cup dan saucer), silverware (sendok, garpu dan pisau), glassware (gelas), dan linen (moulton, table cloth dan napkin) dan table accessories (ashtray, salt and pepper shaker, flower vase, sugar bowl, dan table number). Pembekalan nama-nama peralatan tesebut dianggap penting untuk disampaikan mengingat hampir digunakan oleh setiap industri restoran dan hotel manapun.

Setelah siswa/siswi SMKN memahami namanama peralatan, selajutnya mereka diajarkan untuk menata table cloth. Pada dasarnya, ada 9 tahapan umum dalam menyusun table cloth. Pertama, mereka diingatkan untuk selalu memeriksa dan memastikan kondisi meja dan kursi dalam keadaan baik dan kokoh. Selanjutnya, peserta dilatih untuk memasang molton dan taplak meja, hingga melipat napkin dan terpasang di meja.
Menata meja tidak hanya memasang table cloth dan melipat napkin saja, tetapi juga melengkapi accessories yang ada diatasnya. Siswa/siswi mempraktikan tata cara menyusun table accessories (flower vase, menage, table number), show plate yang diletakan ditengah sisi meja makan dengan jarak $2 \mathrm{~cm}$, cutlery dan silverware yang diletakan dekat dan sejajar dengan show plate dan dinner plate. Selain itu, juga mempraktikan menyusun water goblet $2 \mathrm{~cm}$ diatas dinner knife. Bread and butter place disusun dekat kiri garpu paling kiri $(3 \mathrm{~cm})$, dan butter spreader ditas piring $B \& B$ plate. Akhir persiapan table cloth diakhiri dengan meletakan guest napkin diatas show plate.

Meja prasmanan (buffet) dipersiapkan oleh siswa sesuai dengan konsep yang ditentukan. Selain itu, peserta praktik dilatih untuk menghafal hidangan menu secara detail, guna mampu menjelaskan menu ataupun menjawab pertanyaan dari tamu. Sebelum proses pelaksanaan dimulai, dosen pembimbing melakukan briefing tentang tata cara menyambut, melayani, menghidangkan, hingga membersihkan meja.

\section{b. Divisi Tata Boga}

Tema menu yang dipilih untuk praktik tata boga adalah Balinese Foods. Adapun sajian utama (main course) antara lain, Ayam Betutu, Sate Lilit Ikan, Lawar Sayur, dan Plecing Kangkung. Selain itu, menu dessert yang disajikan antara lain, Biji Salak, Bubur Ketan 
Hitam, dan Klepon.

Pada tahap persiapan, siswa/siswi SMKN diajarkan untuk memahami menu planning dan bahan baku produk dapur yang akan diolah. Setiap anggota tim memastikan sudah mempersiapkan peralatan yang akan dipergunakan. Sebelum proses memasak, instruktur chef mendemonstrasikan tentang prinsip dasar, cara, dan proses memasak makanan. Setelah dosen pembimbing mengilustrasikan singkat teknik memasak, selanjutnya siswa selaku Cook mempraktikan memasak dengan melihat buku panduan yang telah diberikan.

\section{c. Demonstrasi Fruit Carving}

Instruktur didampingi oleh dosen tata boga mendemonstrasikan seni mengukir buah dengan memperhatikan nilai estitika didalamnya. Adapun buah yang digunakan antara lain, semangka, melon, dan pepaya. Buah tersebut pada umumnya dipilih, karena dianggap objek yang padat, sehingga mudah untuk diukir dan siswa juga mudah untuk mencobanya. Ketiga buah tersebut divisualisasikan kedalam bentuk bunga.

Instruktur memberikan 3 (tiga) kunci dasar dalam fruit carving, antara lain: kemauan, kreatifitas, dan ketekunan. Pembimbing meyakini bahwa peserta praktik bisa memperlajarinya asalkan menjalaninya dengan sungguh-sungguh. Secara teknis, pisau yang digunakan harus mempunyai ujung runcing dan tajam. Tujuannya agar para pegiat fruit carving, khususnya siswa/siswi SMKN dapat mengukir secara apik, unik, dan detil sehingga terlihat menjadi sebuah maha karya seni yang memukau.

\section{d. Demonstrasi Ice Carving}

Dosen pembimbing dan 2 (dua) instruktur/ice sculptors mendemonstrasikan seni memahat es kedalam bentuk sebuah objek "Angsa" dari sebongkah es khusus. Secara umum, ada instruktur/ice sculptors mengilustrasikan teknik dasar dalam ice carving. Pertama, melunakan es sebelum memotong. Hal ini bertujuan agar suhu es menyesuaikan dengan suhu ruangan. Es yang siap dapat dilihat pada setiap bagian sisi yang sepenuhnya jernih dan biasanya membutuhkan waktu 30 menit. Kedua, siswa diajarkan untuk memahami penggunaan peralatan, seperti fungsi pisau bergerigi besar, talenan besar, pemecah es, pisau pengupas tajam dan linen. Langkah teknik selanjutnya seperti, pemotongan dari tengah, pengetokan, perbaikan ketidaksempurnaan, dan penghalusan. Selain itu, kunci dari keterampilan ice carving yang disampaikan oleh instruktur/ice sculptors kepada siswa adalah kecepatan dan ketepatan dengan banyak berlatih.

\section{Proses Pelaksanaan}

\section{a. Divisi Tata Hidang}

Proses ini diawali dengan tahap Greeting the guest atau sambutan ramah oleh hostess restaurant selaku siswa/siswi SMKN.

$$
\text { Pendidikan }
$$


Selanjutnya, masuk ke ta tahap Escorting and Sitting the guest dimana tamu diantar oleh mereka ke meja dan dibantu menarikan kursi ketika tamu akan duduk. Setelah tamu duduk, Waiter/Waitress atau selaku peserta praktik menghampiri meja untuk menuangkan air es (Pouring ice water) ke goblet glass dari arah sebelah kanan, dibantu dengan waiter lainnya untuk membantu membuka dan meletakan napkin dipangkuan tamu. Tahap selanjutnya adalah "Serving bread and butter", yang artinya siswa/siswi menyajkan roti dan mentega sebagai makanan pendamping.

Peserta didik menerapkan teori "Presenting the menu/taking order", yang mana mereka memberikan daftar menu dari sisi kiri tamu, juga responsif membantu tamu jika mereka mengalami kesulitan terhadap menu yang ditawarkan. Ketika tamu mulai memilih menu makanan, waiter/siswa mencatat pesanan tamu, lalu memberikannya pada bagian terkait. Langkah "Adjustment" dilakukan oleh waiter guna menyesuaikan antara peralatan makan dan menu yang telah dipesan. Ketika makanan siap, waiter/siswa menyajikan hidangan (Serving the food) sesuai dengan aturan yang telah ditentukan.

Setelah tamu selesai santap makanan, tahap "Clear up" dilakukan oleh peserta didik dengan cara mengambil peralatan kotor. Pada saat hidangan dessert, waiter/siswa mengambil peralatan yang tidak digunakan, lalu disambung dengan langkah "Crumbing down" atau membersihan sisa-sisa makanan di meja dengan menggunakan napkin dan piring. Setelah hidangan dessert selesai, waiter/siswa masuk ke tahap "Presenting coffee or tea" dengan menawarkan kopi dan the kepada tamu.

Sebelum tagihan diberikan, captain waiter/siswa menanyakan komentar tamu mengenai kualitas pelayanan, cita rasa hidangan dan minuman sebagai indikator kepuasan tamu, serta evaluasi untuk kedepannya. Selanjutnya, tahap "Presenting the bill' atau memberikan tagihan pesanan dengan menggunakan check tray. Setelah selesai pembayaran, captain \& waiter (siswa) melakukan tahap "Bid Farewell" dengan cara responsif membantu menarik kursi pada saat tamu akan berdiri dan mengucapkan terima kasih. Tahap akhir pada proses ini adalah "Table setting" dimana saat tamu meninggalkan meja, waiter/siswa melakukan pengaturan ulang meja agar dapat dipakai kembali oleh tamu selanjutnya.

b. Divisi Tata Boga 
Sebelum sajian makanan diantarkan ke meja tamu, peserta praktik memastikan sepenuhnya makanan siap, mulai dari jumlah, rasa, kebersihan, kesegaran, dan tampilan yang menarik. Instruktur mengingatkan kepada siswa untuk perlunya memperhatikan hal-hal tersebut guna menjamin kepuasan tamu. Setelah semua menu sajian sudah diantarkan ke meja tamu dan buffet, peserta praktik tetap berjaga di dapur untuk mengerjakan pesanan tambahan atau permintaan lainnya. Siswa/siswi diajarkan untuk memiliki rasa tanggung jawab, dengan cara membersihkan dan menyimpan peralatan yang telah digunakan.

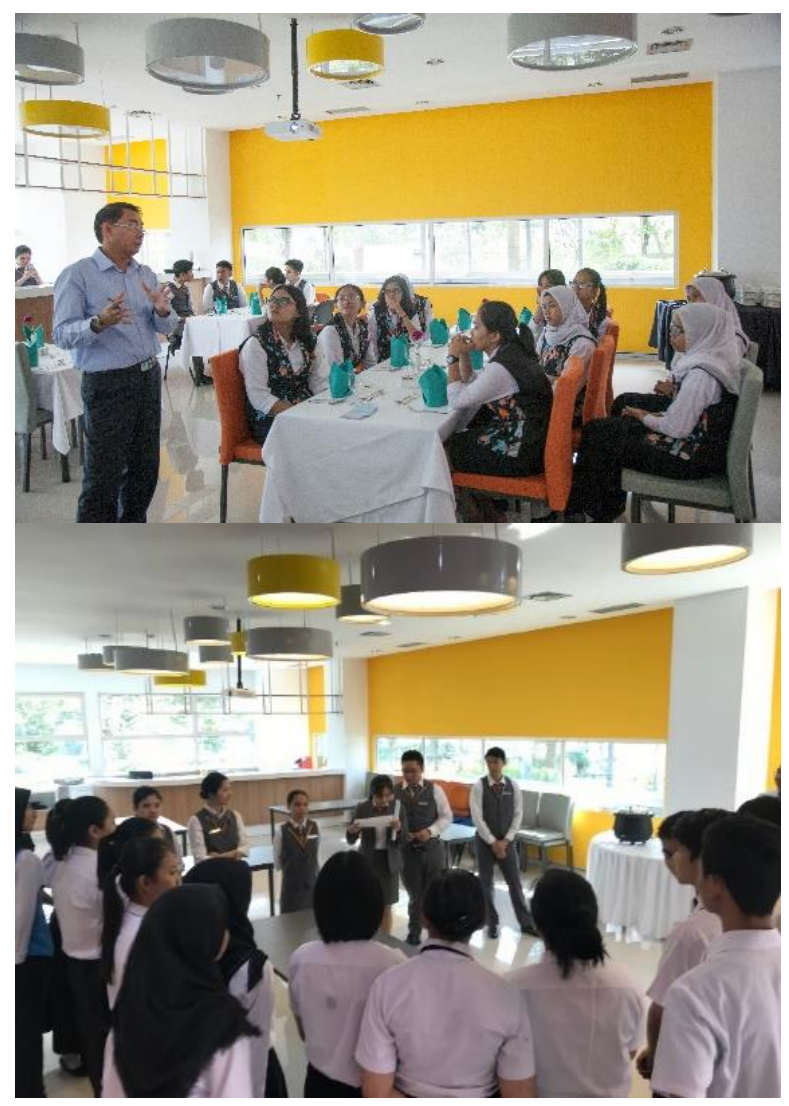

Gambar 1. Persiapan Tata Hidang

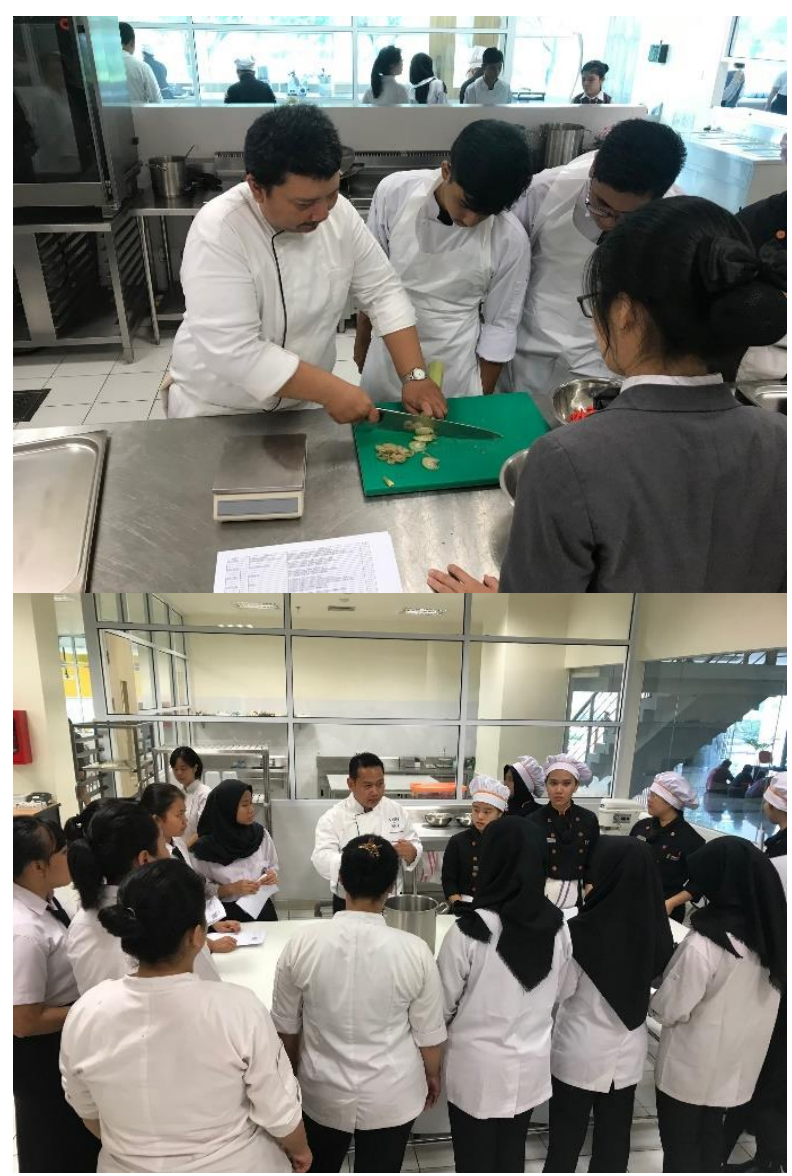

Gambar 2. Persiapan Tata Boga

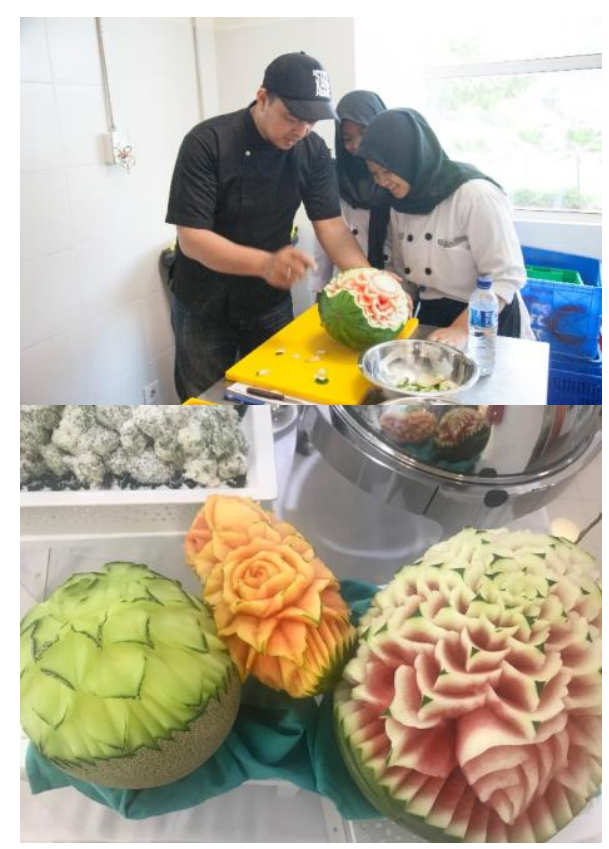

Pendidikan 


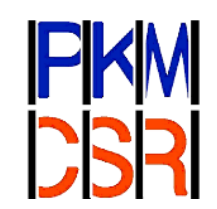

Prosiding PKM-CSR, Vol. 2 (2019)

e-ISSN: 2655-3570

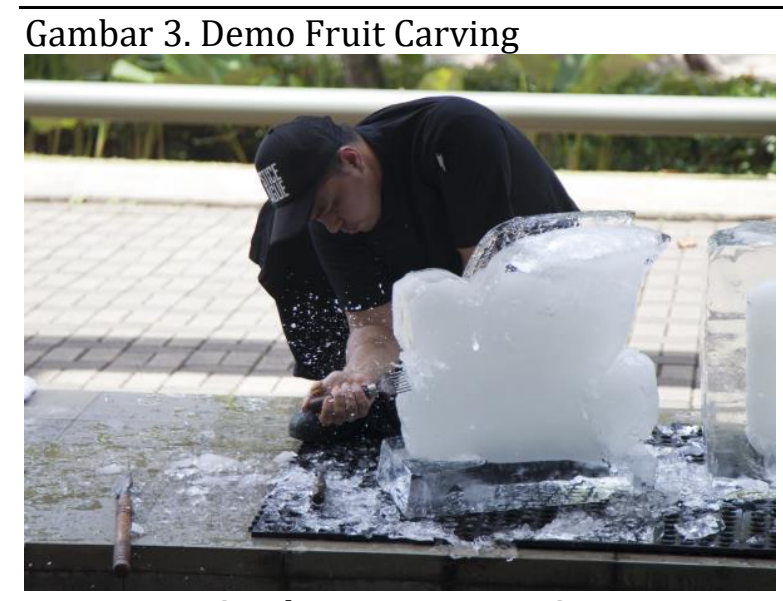

Gambar 4. Demo Ice Carving

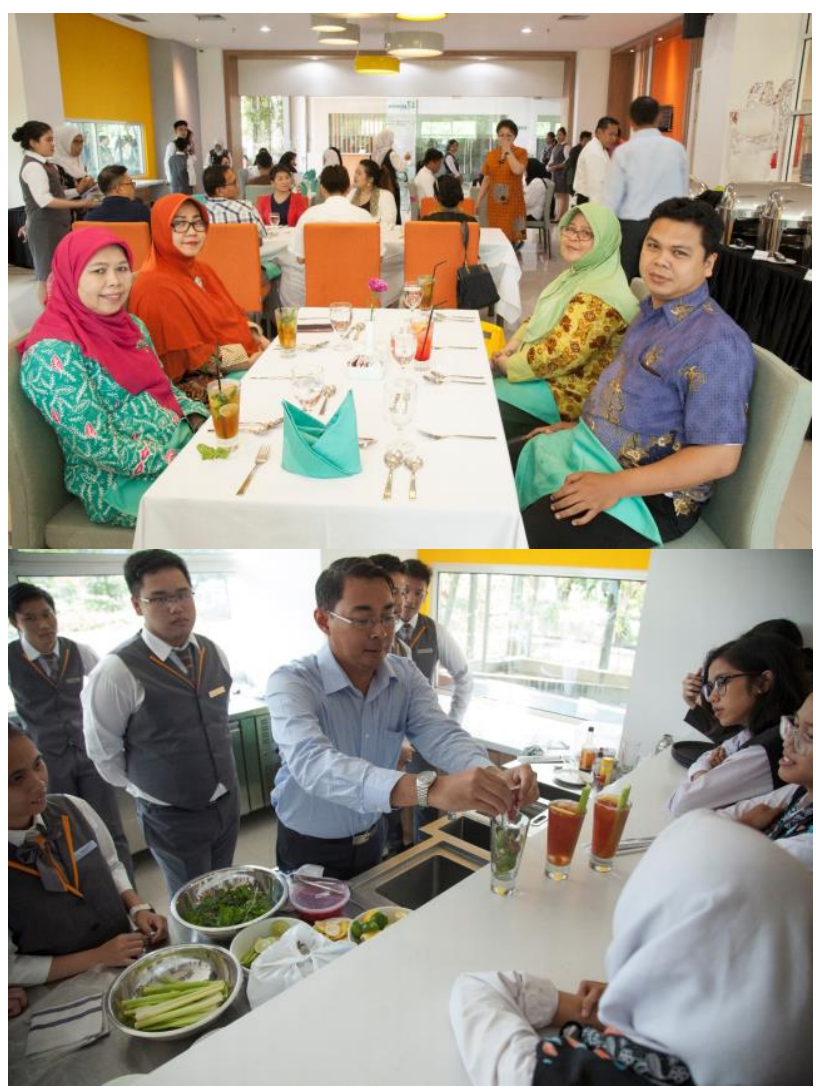

Gambar 5. Pelaksanaan Praktik Bersama
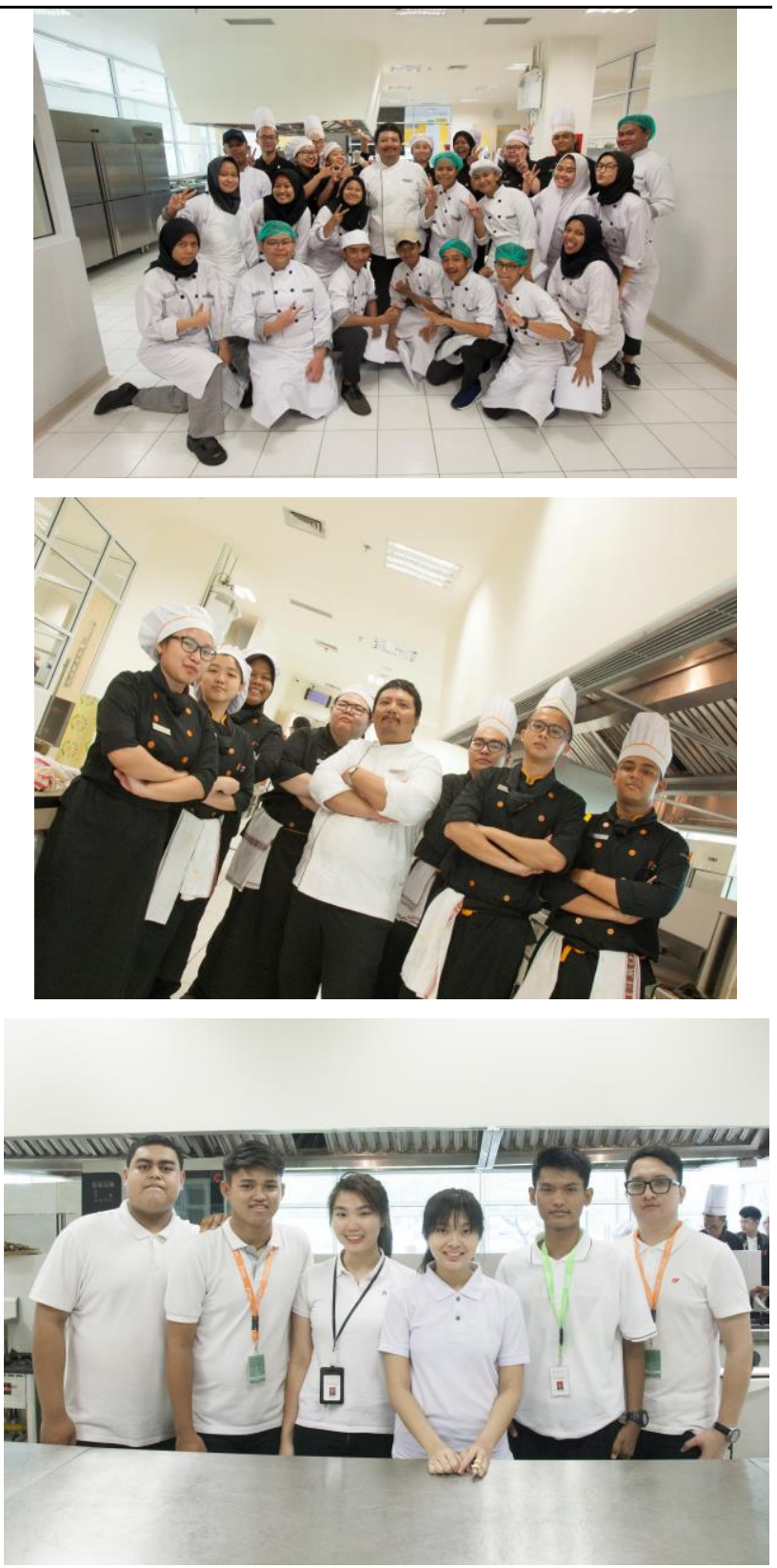

Gambar 6. Tim Tata Boga \& Perlengkapan 

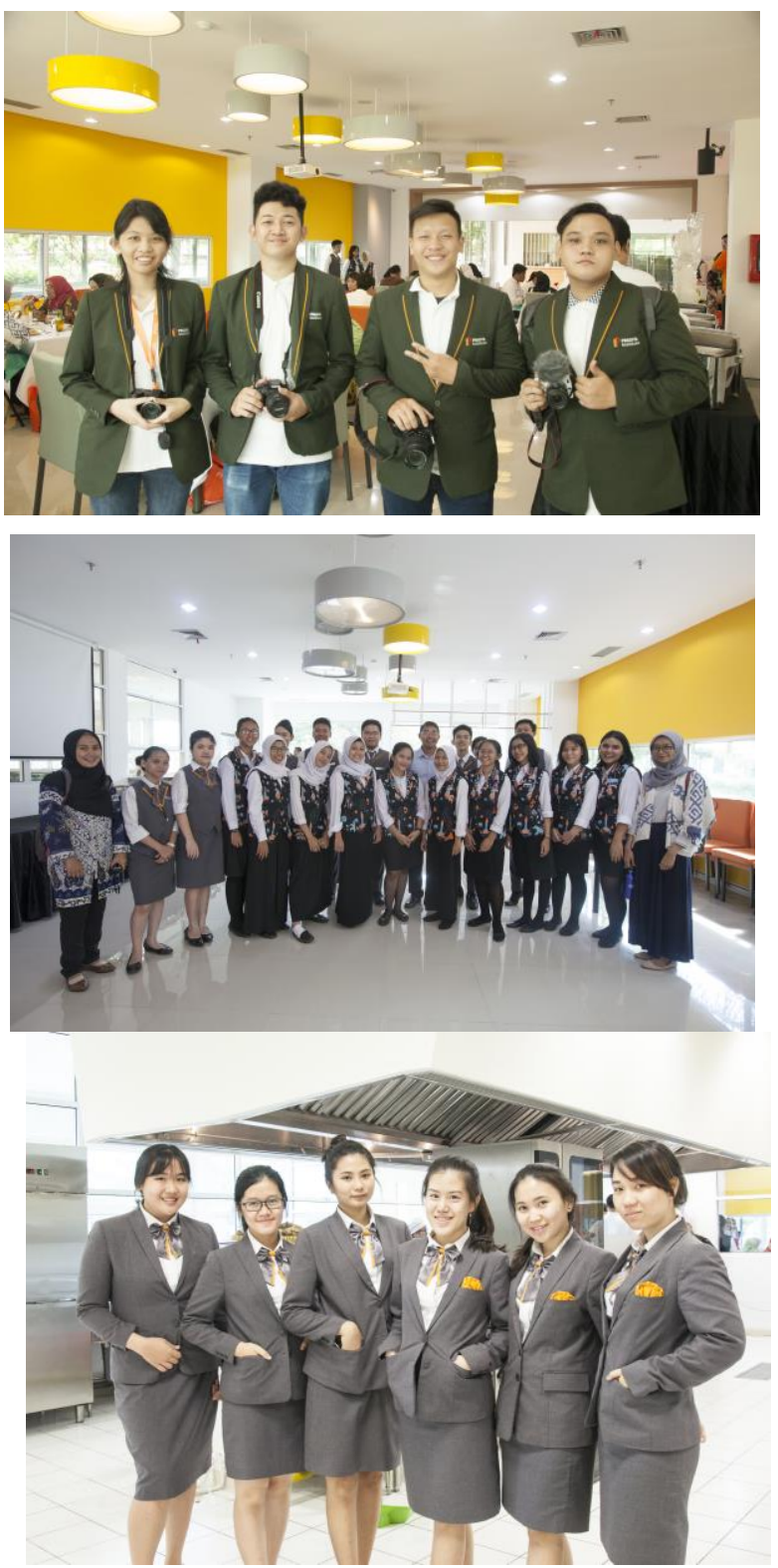

Gambar 7. Tim Dokumentasi, Tata Hidang \& Liaison Officer

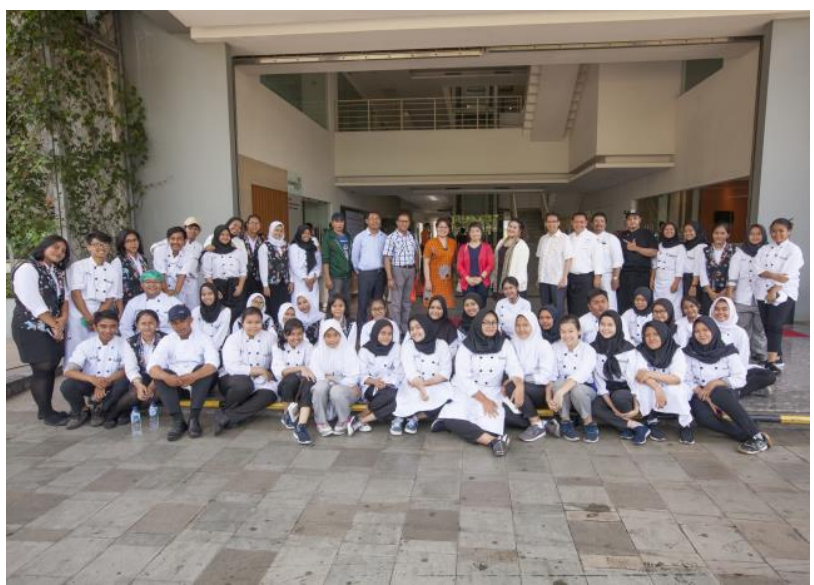

Gambar 8. Siswa SMKN, Guru \& Tamu Undangan

\section{SIMPULAN}

1. Praktik Bersama atau Joint-Practicum telah berhasil dilakukan, yang mana kolaborasi antar pelajar menghasilkan kekompakan dan ketepatan. Hal ini dapat terlihat dari hasil yang memuaskan dalam mengoperasionalkan restoran dengan jumlah tamu yang banyak dan waktu yang terbatas.

2. Keluaran dari hasil penyelenggaran praktik bersama/joint-practicum adalah peserta merasa mampu bekerja sama dengan orang lain di lingkungan yang baru. Kegiatan ini melatih siswa agar merasa tebiasa dan cepat beradaptasi dengan orang-orang yang baru dikenal.

3. Siswa/siswi SMKN merasa puas dengan pengayaan materi praktik yang diselenggarakan oleh Pradita Institute. Hal ini dapat diukur dengan pernyataan puas mereka terhadap kualitas dosen pembimbing \& instruktur, kualitas masakan, konsep acara \& demonstrasi fruit \& ice carving, dan kelengkapan fasilitas 
laboratorium restaurant dan kitchen yang terintegrasi.

4. Peserta praktik yang berada di divisi tata hidang merasa lebih percaya diri saat berhadapan dengan tamu. Selain itu, mereka dapat memahami sepenuhnya tentang prosedur tata hidang pada sebelum/saat restoran beroperasi.

5. Peserta praktik yang berada di divisi tata boga merasa mendapatkan pengalaman baru tentang resep dan teknik memasak masakan Bali, yang diolah, disajikan dan dinikmati segera oleh para tamu di lab resto.

\section{REFERENSI}

Bartono., \& Ruffino. (2010). Tata Boga Industri. Yogyakarta: Andi.

Hardina, D., Middleton, J., Montana, S., \& Simpson, R. (2007). An Empowering Approach to Managing Social Service Organizations. New York: Springer Publishing Company.

Idayati, FI. Nurwahyuni., dan Pratiwi, Yustina. (2008). Garnish Buah Dan Sayur Hiasan
Pengundang Selera. Yogyakarta: Kanisius.

Lall, M., \& Sharma, S. (2009). Personal Growth \& Traning \& Development. New Delhi: Excel Books.

Mertayasa, AIG. (2012). Food and Beverage Service Operational. Yogyakarta: Andi.

Poulin, J. (2005). Strenghts-Based Generalist Practice: A Collaborative Approach second edition. Belmont USA: Thompson Books/Cole.

Setiawan, H., \& Rika A. H. (2008). Tata Letak Pabrik. Andi Offset. Yogyakarta

Soekresno, INR., \& Pendit. (1996). Petunjuk Praktek Pramusaji Food \& Beverage Service :Buku Panduan Sekolah Pariwisata \& Perhotelan. Jakarta: PT. Gramedia Pustaka Utama.

Wiwoho, A. (2008). Pengetahuan Tata Hidang. Jakarta: Erlangga. 